\title{
C-6 Ceramide Induces p53 Dependent Apoptosis in Human Astrocytoma Grade4 (Glioblastoma Multiforme) Cells
}

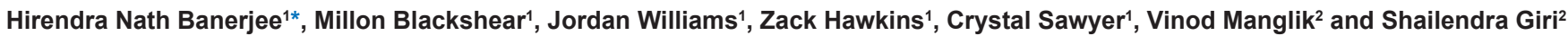

${ }^{1}$ Department of Biological Sciences, Elizabethcity State University under The University of North Carolina, Elizabethcity, NC-27909

${ }^{2}$ Department of Internal Medicine, Mayo Clinic, 200 First St. S.W. Rochester, MN 55905

\begin{abstract}
Ceramide is composed of sphingosine and a fatty acid found in large concentration within the cell membrane and often acts as a signaling molecule for various functions including programmed cell death. In the present investigation, we observed that C6-ceramide induces p53-dependent apoptosis and effectively killed the Astrocytoma grade4 (Glioblastoma Multiforme) HTB12 cell lines. Ceramide-induced cell death was confirmed by Trypan blue assay which showed about $65 \%$ cells dying from ceramide treatment. Apoptosis was confirmed by Caspase3 ELISA assay and DNA fragmentation assay. The p53 induction was confirmed by immunoblot studies. Since C6 Ceramide induces apoptosis in Glioblastoma cells, it may be employed in chemotherapeutic strategy to treat this highly malignant brain cancer.
\end{abstract}

Keywords: Ceramide; Apoptosis; p53; ELISA; Astrocytoma; Caspase

\section{Introduction}

Astrocytomas are the most common primary brain tumors in humans. They are classified according to malignancy (astrocytoma, anaplastic astrocytoma, and glioblastoma multiforme [GBM]). The most recent statistics suggest that more than 18,000 new cases of brain cancer were reported in 2004 in the United States. Despite advances in neuroimaging, microsurgical techniques, radiotherapy, and chemotherapy, the prognosis for these patients remains poor. With aggressive treatment, including surgical resection, focused radiotherapy, and systemic and/or local chemotherapy, the mean survival for these patients is still measured in months. Consequently, identifying areas of study to improve outcomes is an important focus of research.

Ceramide is a sphingosine, which is a lipid messenger in nerve cells. Sphingomyelin is present in cell membranes and is the source of free ceramide and sphingosine. Sphingomyelin is preferentially concentrated in the outer leaflet of the plasma membrane of most mammalian cells; it comprises sphingosine (a long chain sphingoid base backbone), a fatty acid, and a phosphocholine head group. Ceramide is composed of a sphingoid base with a fatty acid in amide linkage. Sphingomyelin was initially considered only a structural component of plasma membrane; however, several investigations established the involvement of sphingolipids and its metabolites in key events of signal transduction associated with cell regulation, cell differentiation, and apoptosis [1-3]. The sphingomyelin pathwayassociated signal transduction pathway mediates the action of several extracellular stimuli that lead to important biochemical and cellular effects [4-8]. This pathway is initiated by the activation of two distinct forms of sphingomyelinase (SMase), a membrane-associated neutral sphingomyelinase [9] and an acidic sphingomyelinase [10], which reside in the caveola and the endosomal-lysosomal compartment. Each type of SMase hydrolyzes the phosphodiester bond of sphingomyelin to yield ceramide and phosphocholine. Proinflammatory cytokines (tumor necrosis factor- $\alpha$ TNF- $\alpha$; interleukin- $1 \beta$, IL-1 $\beta$; interferon- $\gamma$, IFN- $\gamma$ ) and bacterial lipopolysaccharides have been shown as potent inducers of SMases. One of the products, ceramide, has emerged as a second messenger molecule that is considered to mimic most of the cellular effects of cytokines and lipopolysaccharide in terminal differentiation, apoptosis, and cell cycle arrest.

C6-Ceramide is a second messenger in neurons. It is a lipid mediator of cell growth and apoptosis in cells. Ceramide is able to cross the Blood Brain Barrier (BBB), which makes it important in fighting against brain cancer [11]. C6-ceramide is believed to induce apoptosis in cells $[7,8,12]$. There are other types of ceramide and they can be found in all cells at some point in their life cycle. However, C6 Ceramide is supposed to be able to cross the BBB, which makes it important in the fight against brain cancer.

A naturally occurring protein known as p53 (also known as TP53) often found in normal cells, functions as a transcription factor that regulates cell cycles and confers stability of the cells by preventing genome mutation [13] and is considered to be a tumor suppressor. Apoptosis or programmed cell death can proceed via p53 dependent or independent pathway. In this study, we investigated the effect of C6Ceramide on the Human Astrocytoma cell lines to study its therapeutic effects and, also, the role of p53 in Ceramide-induced cell death.

\section{Materials and Methods}

\section{Cell culture}

Human grade4 Astrocytoma cell line HTB12 were obtained from ATCC (VA, USA) and cultured in L-15 medium containing $10 \%$

${ }^{*}$ Corresponding author: Dr. Hirendra Nath Banerjee, Professor, Department of Biological Sciences, Elizabethcity State University, University of North Carolina 1704 Weeksville Road, Elizabethcity, NC 27909, USA, Tel: 252-335 3241; Fax: 252 335 3697; E-mail: bhirendranath@mail.ecsu.edu

Received December 19, 2011; Accepted February 09, 2012; Published February 13, 2012

Citation: Banerjee HN, Blackshear M, Williams J, Hawkins Z, Sawyer C, et al (2012) C-6 Ceramide Induces p53 Dependent Apoptosis in Human Astrocytoma Grade4 (Glioblastoma Multiforme) Cells. J Cancer Sci Ther 4: 012-015. doi:10.4172/1948-5956.1000104

Copyright: @ 2012 Banerjee HN, et al. This is an open-access article distributed under the terms of the Creative Commons Attribution License, which permits unrestricted use, distribution, and reproduction in any medium, provided the original author and source are credited. 
Citation: Banerjee HN, Blackshear M, Williams J, Hawkins Z, Sawyer C, et al. (2012) C-6 Ceramide Induces p53 Dependent Apoptosis in Human Astrocytoma Grade4 (Glioblastoma Multiforme) Cells. J Cancer Sci Ther 4: 012-015. doi:10.4172/1948-5956.1000104

fetal bovine serum, $50 \mathrm{U} / \mathrm{ml}$ penicillin, and $50 \mathrm{ug} / \mathrm{ml}$ streptomycin in a standard cell culture incubator at $37^{\circ} \mathrm{C}$ in the presence of $5 \% \mathrm{CO}_{2}$.

\section{Reagents}

C6 Ceramide was purchased from Sigma Chemicals, USA. Trypan Blue, p53 antibody and immunoblot materials were purchased from Fisher Scientific, USA. Caspase 3 assay kit was purchased from Clontech USA. Single stranded DNA Apoptosis ELISA kit was purchased from Chemicon, USA.

\section{Ceramide preparation}

Stock solution of Ceramide was prepared in DMSO and stored at $-20^{\circ} \mathrm{C}$; when added to aquatic medium, the final concentration of DMSO did not exceed $0.12 \%$. A brief sonication cycle was used to dissolve ceramide in the cell culture medium. Dose: $1 \mathrm{ug} / \mathrm{ml}$ of C6 Ceramide was used only once for 48 hours of incubation in each case of assay since this dose and time of incubation was found to be nearest to the IC50 for these cell lines.

\section{Trypan blue viability assay}

Viability of cells was assayed by the dye exclusion stain technique. In this assay, cells with an intact membrane are able to exclude dye, whereas without an intact membrane they retain the dye. In brief, $1 \times 10^{6}$ cells were suspended in phosphate buffer saline. A 1:1 dilution of the cell suspension was made in $0.4 \%$ Trypan blue and loaded into a hemocytometer. After 1-2 minutes of incubation with the dye cells were counted immediately as prolong incubation would cause viable cells to die. Then the percentage of stained and unstained cells was calculated which would represent the dead and live cells [5].

\section{Single stranded DNA apoptosis ELISA kit}

The protocol described in manufacturer's kit was followed. In brief, this assay is based on the principle of the selective denaturation of DNA in apoptotic cells and detection of denatured DNA (ssDNA) by a nucleosomal monoclonal antibody in an ELISA format. This assay includes attachment of cells to 96 well plates, treatment of cells with ceramide, fixing by formamide and detection of ssDNA in apoptotic cells by incubation with primary monoclonal antibody and peroxidaselabeled secondary antibody. This assay was performed by an ssDNA Apoptosis ELISA kit from Chemicon International Inc. (CA, USA) and by using a standard microplate reader at $405 \mathrm{~nm}$.

\section{Caspase- 3 assay}

This assay was performed following the protocols of Apoalert Caspase colorimetric assay kit from Clontech Corporation (CA, USA). Ceramide treated cells and untreated experimental control cells were lysed by cold cell lysis buffer, centrifuged, and the supernatant was incubated with $50 \mu$ of $2 \mathrm{X}$ reaction buffer along with $5 \mu \mathrm{l}$ of $1 \mathrm{mM}$ Caspase -3 substrate (DEVD-pNA, $50 \mu \mathrm{M}$ final concentration) to each tube and incubated for $37^{\circ} \mathrm{C}$ for one hour in a water bath. The samples were then read in a microplate reader at $405 \mathrm{~nm}$.

\section{Immunoblot analysis for P53}

Following 6,12,24 and 48 hours of incubation in the presence or absence of Ceramide, astrocytomas were scraped off, washed with Hank's buffer, and homogenized in 50mM Tris- $\mathrm{HCl}$, pH 7.4, containing protease inhibitors. After electrophoresis, the proteins were transferred on to a nitrocellulose membrane and the $\mathrm{p} 53$ band was visualized by immunoblotting with monoclonal antibodies against p53.

\section{Statistical analysis}

Each experiment was repeated three times and graphs were generated considering the mean, ANOVA and the standard error using the EXCEL software.

\section{Results}

To study the cytotoxic effects of Ceramide on the Astrocytoma cells, the Trypan Blue Assay was used. As shown in Figure 1, Ceramide killed cells at a much higher rate than the DMSO or the control (without DMSO).

The antibody in the ssDNA ELISA assay selectively binds to only DNA that has become fragmentized which exposes nucleosomal proteins, characteristic of apoptotic cell death. This observation provided conclusive evidence that the ceramide is killing the cells by inducing apoptosis. The data also show (Figure 2) that ceramide is killing by apoptosis at a higher rate than the untreated control human astrocytoma cells

Caspases are families of $\mathrm{Ca}^{++}$dependent cysteine proteases which are the executioners of apoptosis (programmed cell death), necrosis (accidental cell death), or inflammation (due to harmful stimuli). These enzymes get activated when cells are dying. As shown in Figure 3 , the level of caspase- 3 enzyme found in ceramide treated cells was significantly higher than that of the control cells. The programmed cell death can be either p53 dependent or independent. In order to reveal which pathway, cells were exposed to ceramide for various time periods (6-48 hrs) and then proteins were extracted and subjected to

\section{TRYPAN BLUE ASSAY}
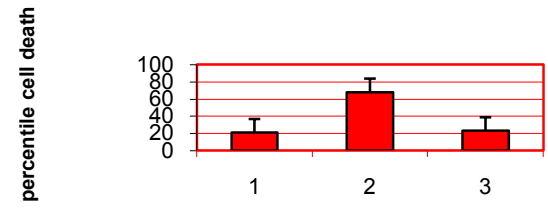

CONTROL CERAMIDE DMSO

Figure 1: The Trypan Blue Assay. This assay showed that Ceramide (2) killed human astrocytoma cells at a higher rate than control (without DMSO, 1) and DMSO (3).

\section{APOPTOSIS ssDNA ELISA ASSAY}

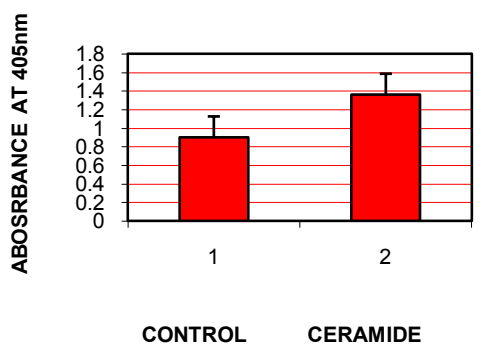

Figure 2: Ceramide-induced apoptotic cell death. Cell death rate is higher in ceramide treated cells than control as shown by higher absorbance at $405 \mathrm{~nm}$. 
acrylamide gel electrophoresis followed by Western blot analysis. A 53 kilo Dalton bands appeared on the gel signifying the induction of p53 at different time intervals at a fixed dose of C6 Ceramide and which was undetectable at parallel time course in control cells as shown in Figure 4.

\section{Discussion}

Ceramide, a product of sphingolipid metabolism, is generated in response to various stress stimuli, such as tumor necrosis factor-alpha, CD95/Fas, chemotherapeutic agents, and irradiation. Ceramide may modulate the biochemical and cellular processes that lead to apoptosis. However, the mechanisms by which ceramide regulates apoptotic events are not fully defined. It is believed that the biological effect of ceramide depends on its concentration, the activation or differentiation status of the cell, and the time frame of action.

Several studies support a role for the hydrolysis of sphingomyelin as a stress-activated signaling mechanism in which ceramide plays a role in growth suppression and apoptosis in various cell types including glial and neuronal cells [10-12,14-16]. Ceramide activates the proteases (pr) of the interleukin-converting enzyme (ICE) family (especially prICE/YAMA/CPP32), the protease responsible for cleavage of poly (ADP)-ribose polymerase, and that the activation of prICE by ceramide and induction of apoptosis are inhibited by overexpression of $B c l-2$. Addition of exogenous ceramides or sphingomyelinase to cells induces

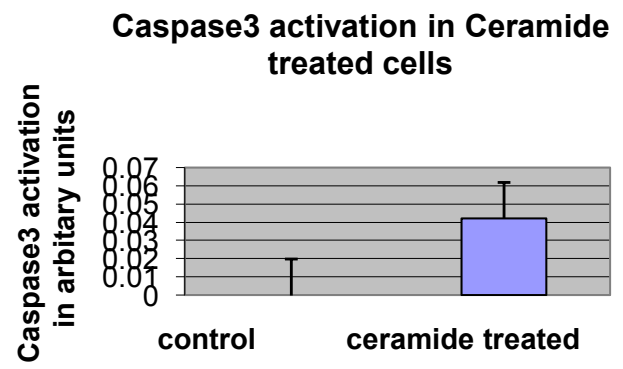

Figure 3: Caspase 3 activation in response to C6 Ceramide stimulation. Ceramide treated human astrocytoma cells exhibits an enormous level of caspase 3 activation as compared to Control.

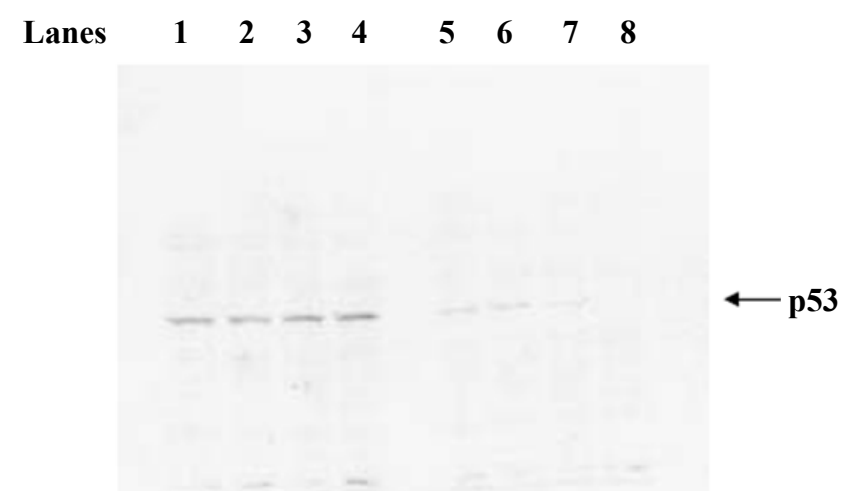

Figure 4: Western blot analysis of ceramide treated cells. Blots were analyzed against p53 monoclonal antibody.

From left to right: Lane 1,2,3,4 show induction of p53 due to C6-Ceramide stimulation for $6,12,24$ and 48 hours of incubation.

Lane 5, 6, 7 and 8: Control (DMSO) without ceramide stimulation and incubated with parallel time periods $6,12,24$, and $48 \mathrm{hrs}$ of incubation. stress-activated protein kinase-dependent transcriptional activity through the activation of c-jun, and a dominant negative mutant of SEK1, the protein kinase responsible for phosphorylation and activation of stress-activated protein kinase, interferes with ceramideinduced apoptosis [16-24]. These observations also suggest that both $\mathrm{Bcl}-2$ and stress-activated protein kinase function downstream of ceramide in the apoptotic pathway.

In this study on the role of C6-Ceramide in inducing apoptosis in human Astrocytoma cells, we first showed that Ceramide induces cell death. Cell death assays showed that this cell death is mediated by apoptosis which is confirmed by DNA fragmentation analysis and Caspase activation assay. We further studied the role of $\mathrm{p} 53$ protein in Ceramide-induced Apoptosis and found induction of p53 gene by Ceramide treatment. Further research is needed, including full molecular characterization of the enzymes involved in the generation and metabolism of ceramide and developing a more complete understanding of the complex pathways that regulate sphingolipid synthesis. As ceramide generation and metabolism are likely controlled differently among various types of cells, and are potentially altered in multi-drug-resistant cells, signaling pathways and pharmacological manipulation of those pathways will need to be studied across many cell types, and comparisons between chemotherapy-sensitive and drug-resistant cancer cells are needed. The events down-stream from ceramide generation that result in cell death also remain to be completely elucidated, and may vary depending on the type of cell or the prior exposure ofthe cell to cytotoxic stress. Continued work in these important areas could identify potential therapeutic targets, and should increase our understanding of how to best pursue those targets already identified. With drugs that target ceramide now entering clinical trials, and more such agents in pre-clinical development, we can anticipate learning more about the potential for sphingolipids as a cancer therapeutic target in the near future.

\section{Competing Interest}

The authors declare no competing interest.

\section{Acknowledgement}

This research was supported by the Ronald McNair's summer research program. NIH-EARDA grant\#G11HD 34280-05, NASA grant\#NNG04GC42A and NSF- EPSCOR subcontract\# DTD 42501 to Dr. H. N. Banerjee. The authors are grateful to Dr. S. Pramanick and Dr. A. Williams of Morgan State University, MD for their help and advise.

\section{References}

1. Charles AG, Han TY, Liu YY, Hansen N, Guiliano AE, et al. (2001) Taxolinduced ceramide generation and apoptosis in human breast cancer cells Cancer Chemotherapy Pharmacol 47: 444-450.

2. Ogretmen B, Kraveka JM, Schady D, Usta J, Hannun YA, et al. (2001) Molecular mechanisms of ceramide-mediated telomerase inhibition in the A549 human lung adenocarcinoma cell line. J Biol Chem 276: 32506-32514.

3. Ogretmen B, Schady D, Usta J, Wood R, Kraveka JM, et al. (2001) Role of ceramide in mediating the inhibition of telomerase activity in A549 human lung adenocarcinoma cells. J Biol Chem 276: 24901-24910.

4. Biswal SS, Datta K, Kehrer JP (2000) Association between bcl-x (L) and 5 -lipoxygenase activating protein (FLAP) levels in IL-3-dependent FL5.12 cells. Toxicology 160: 97-103.

5. Panasenko OO, Kim MV, Marston SB, Gusev NB (2003) Interaction of the small heat shock protein with molecular mass $25 \mathrm{kDa}$ (hsp25) with actin. Eur J Biochem 270: 892-901.

6. Metkar SS, Anand M, Manna PP, Naresh KN, Nadkarni JJ (2000) Ceramide- 
Citation: Banerjee HN, Blackshear M, Williams J, Hawkins Z, Sawyer C, et al. (2012) C-6 Ceramide Induces p53 Dependent Apoptosis in Human Astrocytoma Grade4 (Glioblastoma Multiforme) Cells. J Cancer Sci Ther 4: 012-015. doi:10.4172/1948-5956.1000104

induced apoptosis in fas-resistant Hodgkin's disease cell lines is caspase independent. Exp Cell Res 255: 18-29.

7. Hartmann D, Lucks J, Fuchs S, Schiffmann S, Schreiber Y, et al. (2012) Long chain ceramides and very long chain ceramides have opposite effects on human breast and colon cancer cell growth. Int J Biochem Cell Biol [Epub ahead of print].

8. Grösch S, Schiffmann S, Geisslinger G (2012) Chain length-specific properties of ceramides. Prog Lipid Res 51: 50-62.

9. Lucci A, Han TY, Liu YY, Giuliano AE, Cabot MC (1999) Modification of ceramide metabolism increases cancer cell sensitivity to cytotoxics. Int J Oncol 15: $541-546$.

10. Lucci A, Giuliano AE, Han TY, Dinur T, Liu YY, et al. (1999) Ceramide toxicity and metabolism differ in wild-type and multidrug-resistant cancer cells. Int $\mathrm{J}$ Oncol 15: 535-540.

11. Kang KH, Lee JH, Kim KC, Ham SW, Kim MY, et al. (2002) Induction of p73beta by a naphthoquinone analog is mediated by E2F-1 and triggers apoptosis in HeLa cells. FEBS Lett 522: 161-167.

12. Bikman BT, Summers SA (2011) Ceramides as modulators of cellular and whole-body metabolism. Clin Invest 121: 4222-4230.

13. Barthlen W, Flaadt D, Girgert R, Conzelmann J, Schweizer P, et al. (2003) Significance of heparin-binding growth factor expression on cells of solid pediatric tumors. J Pediatr Surg 38: 1296-1304.

14. Auzenne E, Leroux ME, Hu M, Pollock RE, Feig B, et al. (1998) Cytotoxic effects of sphingolipids as single or multi-modality agents on human melanoma and soft tissue sarcoma in vitro. Melanoma Res 8: 227-239.

15. Flamigni F, Faenza I, Marmiroli S, Stanic' I, Giaccari A, et al. (1997Inhibition of the expression of ornithine decarboxylase and c-Myc by cell-permeant ceramide in difluoromethylornithine-resistant leukaemia cells. Biochem J 324: 783-789.
16. Takeda Y, Tashima M, Takahashi A, Uchiyama T, Okazaki T (1999) Ceramide generation in nitric oxide-induced apoptosis. Activation of magnesiumdependent neutral sphingomyelinase via caspase-3. J Biol Chem 274: 1065410660.

17. Cai Z, Bettaieb A, Mahdani NE, Legrès LG, Stancou R, et al. (1997) Alteration of the sphingomyelin/ceramide pathway is associated with resistance of human breast carcinoma MCF7 cells to tumor necrosis factor-alpha-mediated cytotoxicity. J Biol Chem 272: 6918-6926.

18. Jayadev S, Liu B, Bielawska AE, Lee JY, Nazaire F, et al. (1995) Role for ceramide in cell cycle arrest. J Biol Chem 270: 2047-2052.

19. Pettus BJ, Bielawska A, Spiegel S, Roddy P, Hannun YA, et al. (2003) Ceramide kinase mediates cytokine- and calcium ionophore-induced arachidonic acid release. J Biol Chem 278: 38206-38213.

20. Spinedi A, Bartolomeo SD, Piacentini M (1998) Apoptosis induced by $\mathrm{N}$-hexanoylsphingosine in CHP-100 cells associates with accumulation of endogenous ceramide and is potentiated by inhibition of glucocerebroside synthesis. Cell Death Differ 5: 785-791.

21. Strachan T, Read AP (1999) Human Molecular Genetics. (2nd edn), Cancer Genetics, New York: Wiley-Liss.

22. Tepper AD, de Vries E, van Blitterswijk WJ, Borst J (1999) Ordering of ceramide formation, caspase activation, and mitochondrial changes during CD95- and DNA damage-induced apoptosis. J Clin Invest 103: 971-978.

23. Tohyama J, Matsuda J, Suzuki K (2001) Psychosine is as potent an inducer of cell death as C6-ceramide in cultured fibroblasts and in $\mathrm{MOCH}-1$ cells. Neurochem Res 26: 667-671.

24. Zimmermann C, Ginis I, Furuya K, Klimanis D, Ruetzler C, et al. (2001) Lipopolysaccharide-induced ischemic tolerance is associated with increased levels of ceramide in brain and in plasma. Brain Res 895: 59-65. 